\title{
SEMEADURA DIRETA COM TRANSPOSIÇÃO DE SERAPILHEIRA COMO METODOLOGIA DE RESTAURAÇÃO ECOLÓGICA ${ }^{1}$
}

\author{
Kelly de Almeida Silva², Sebastião Venâncio Martinss ${ }^{3}$, Aurino Miranda Neto ${ }^{4}$ e Wanuza Helena Campos ${ }^{5}$
}

\begin{abstract}
RESUMO - O objetivo deste estudo foi avaliar o efeito da transposição de serapilheira na semeadura direta como metodologia de restauração ecológica de áreas degradadas. O estudo foi realizado no Viveiro de Pesquisas da Universidade Federal de Viçosa (UFV), em canteiros a céu aberto, com delineamento inteiramente casualizado. Compararam-se três tratamentos distintos, com cinco repetições cada, deixando-se também cinco parcelas como controle. Nas parcelas controle, apenas removeu-se o solo superficial do canteiro. Os demais tratamentos consistiram da semeadura direta de quatro espécies nativas, sendo duas pioneiras (Senna macranthera e Colubrina glandulosa) e duas não pioneiras (Tabebuia serratifolia e Cedrela fissilis). O tratamento 1 constituiu de apenas semeadura direta, o tratamento 2 de semeadura direta com posterior transposição de serapilheira e o tratamento 3 foi constituído de transposição de serapilheira com posterior semeadura direta. A serapilheira foi transposta de um fragmento de Floresta Estacional Semidecidual secundária localizado no Campus da UFV. Após dois anos, o tratamento 2 apresentou maior porcentagem de emergência de plântulas. No tratamento 1 foram encontrados 36 indivíduos arbóreos, oriundos apenas da semeadura. No tratamento 2 haviam 312 indivíduos arbóreos e no tratamento 3, 140, ambos com indivíduos oriundos da semeadura e serapilheira transposta. A transposição da serapilheira influenciou a emergência e estabelecimento das plântulas. S. macranthera e $C$. glandulosa foram as espécies com maior porcentagem de emergência e, portanto, apresentaram potencial para uso em projetos de restauração ecológica através de semeadura direta.
\end{abstract}

Palavras-chave: Restauração florestal; Nucleação; Serapilheira.

\section{DIRECT SOWING WITH TRANSPOSITION OF LITTER AS METHODOLOGY OF ECOLOGICAL RESTORATION}

\begin{abstract}
The objective of this study was to evaluate the effect of the transposition of litter on direct sowing as a method of ecological restoration of degraded areas. The study was conducted in the Nursery Research at Federal University of Viçosa (UFV) in the open construction site, with a completely randomized design. We compared three different treatments with five replicates each, leaving also five plots as control. For the control plots only the topsoil from the construction site was removed. The other treatments consisted of direct sowing of four native species, two pioneers (Senna macranthera and Colubrina glandulosa) and two non-pioneer (Tabebuia serratifolia and Cedrela fissilis). Treatment 1 consisted of only direct sowing, treatment 2 of direct sowing with subsequent transposition of litter and treatment 3 of transposition of litter with subsequent direct sowing. The litter has been transposed from a fragment of secondary semi deciduous forest located on the campus of UFV. After two years, treatment 2 had a higher percentage of emergency of seedlings. In treatment 136 individual trees were found, only from sowing. In treatment 2, there were 312 individual trees and in treatment 3, 140 individuals, both with individuals from sowing and litter transposed. The transposition of litter influenced seed emergency and plant establishment. $\boldsymbol{S}$. macranthera and $\boldsymbol{C}$. glandulosa were the species with the highest percentage of emergency and, therefore, have potential for use in ecological restoration projects through direct sowing.
\end{abstract}

Keywords: Forest restoration; Nucleation; Litter.

\footnotetext{
${ }^{1}$ Recebido em 14.05.2012 aceito para publicação em 07.05.2015

${ }^{2}$ Universidade Federal de Viçosa, Programa de Pós-Graduação em Ciência Florestal, Laboratório de Restauração Florestal (LARF), Viçosa, MG, Brasil.E-mail: <kellyalmeidaenf@yahoo.com.br>.

${ }^{3}$ Universidade Federal de Viçosa, Departamento de Engenharia Florestal, UFV, Laboratório de Restauração Florestal (LARF), Viçosa, MG, Brasil. E-mail: <venancio@ufv.br>.

${ }^{4}$ Universidade Federal de Viçosa, Doutorado em Ciência Florestal, Viçosa, MG, Brasil. E-mail: <aur.neto@gmail.com>.

${ }^{5}$ Universidade Federal de Viçosa, Mestrado em Ciência Florestal, Viçosa, MG, Brasil. E-mail: <wanuzacampos@yahoo.com.br>.
} 


\section{INTRODUÇÃO}

Estima-se que, em todo o mundo, cerca de 1,1 milhão de hectares de florestas tropicais, secundárias e energéticas sejam destruídas anualmente ou são seriamente degradadas pela expansão agropecuária que, juntamente com as atividades de mineração e construção de barragens, estradas e ferrovias, são as principais atividades antrópicas responsáveis pela geração de áreas degradadas (ANDRADE et al., 2003). Por essa razão, a restauração dessas áreas tem-se difundido nos últimos tempos e vem sendo cada vez mais executada, diante da situação na qual se encontram os ecossistemas.

A técnica de restauração de áreas degradadas através do plantio de mudas tem sido utilizada na maioria das situações. No entanto, o desenvolvimento de tecnologias visando à restauração dessas áreas, a custo mais baixo, é imprescindível, tendo em vista que, muitas vezes, essas áreas estão em posse de pequenos proprietários, que possuem pouco ou nenhum recurso disponível para ser empregado no reflorestamento (FERREIRA, 2002).

A semeadura direta apresenta-se como técnica promissora, uma vez que a deposição dos propágulos diretamente no solo possibilita estimular o processo de nucleação a baixo custo, já que dispensa a fase de produção de mudas em viveiros (MARTINS, 2007; 2009). Inclui-se nesse contexto também a transposição de serapilheira.

A semeadura direta é uma forma de ajudar na autorrestauração de uma área degradada, de forma a propiciar o adensamento e enriquecimento do banco de sementes do solo. Através da semeadura direta de espécies nativas iniciais ou tardias, é possível promover o recobrimento do solo e o enriquecimento de um ecossistema florestal degradado (ARAKI, 2005).

A semeadura direta consiste na introdução de sementes de determinadas espécies florestais diretamente no solo da área a ser reflorestada. Essa técnica é recomendada para espécies pioneiras e secundárias iniciais, em áreas com ausência de vegetação e também para as espécies secundárias tardias e clímax, quando se trabalha com o enriquecimento de florestas secundárias (KAGEYAMA; GANDARA, 2004).

O sucesso da semeadura direta depende da criação de um microssítio com condições favoráveis para uma rápida germinação (SMITH, 1986), principalmente nos 30 primeiros dias, que são considerados um período crítico para o estabelecimento de mudas de espécies florestais via semeadura direta (MENEGHELLO; MATTEI, 2004).

A transposição da serapilheira também constitui técnica de restauração de áreas degradadas. A sua utilização parte do pressuposto de que a serapilheira contém grande parte do banco de sementes de espécies pioneiras, de nutrientes e de matéria orgânica. Dessa forma, após a germinação, as plântulas encontrarão condições mais adequadas para seu estabelecimento e desencadearão o processo sucessional na área como um todo (MARTINS, 2007).

A serapilheira florestal é constituída por material vegetal depositado na superfície do solo, como folhas, cascas, ramos, flores, inflorescências, frutos, sementes e fragmentos vegetais não identificáveis (CIANCIARUSO et al., 2006). Além de conter sementes de espécies de diferentes formas de vida, a serapilheira fornece nutrientes, matéria orgânica e microrganismos essenciais para a recuperação da fertilidade e da atividade biológica do solo (RODRIGUES et al., 2010). A serapilheira ainda produz sombra e retém umidade, criando condições microclimáticas que favorecem a germinação de sementes e o estabelecimento de plântulas (MORAES et al., 1998).

Portanto, o objetivo deste estudo foi avaliar o efeito da transposição de serapilheira na semeadura direta, como metodologia de restauração ecológica de áreas degradadas.

\section{MATERIAL E MÉTODOS}

O estudo foi realizado no Viveiro de Pesquisas do Departamento de Engenharia Florestal da Universidade Federal de Viçosa (UFV), em Viçosa, Minas Gerais (2045'14"S e 42\%45'53"O).

O clima na região é do tipo Cwb (Köppen), mesotérmico com verões quentes e chuvosos e invernos frios e secos. A temperatura média anual é de $21,8^{\circ} \mathrm{C}$ e a precipitação pluviométrica média anual, $1.314 \mathrm{~mm}$ (CASTRO et al., 1983).

O experimento foi montado em canteiros a céu aberto, com dimensões de $1 \mathrm{~m}^{2}$ cada canteiro, delimitado por blocos de concreto em delineamento inteiramente casualizado (DIC). Para simular uma situação de solo degradado e evitar contaminações com sementes já 
existentes no solo dos canteiros, foi removida uma camada de $10 \mathrm{~cm}$ do solo superficial dos canteiros antes da semeadura e da transposição da serapilheira.

Compararam-se três tratamentos distintos, com cinco repetições em cada tratamento, totalizando 15 canteiros.

O tratamento 1 ( $\mathrm{T} 1$ ) consistiu da semeadura direta de quatro espécies nativas, sendo duas pioneiras e duas não pioneiras, no solo dos canteiros, com 30 sementes de cada espécie, por repetição.

O tratamento 2 (T2) consistiu da semeadura direta de quatro espécies nativas, sendo duas pioneiras e duas não pioneiras, no solo dos canteiros, com 30 sementes de cada espécie, por repetição. Sobre as sementes foi depositada uma camada de serapilheira cobrindo todos os canteiros deste tratamento.

O tratamento 3 (T3) consistiu da deposição da camada de serapilheira nos canteiros e da semeadura direta sobre essa camada de serapilheira de quatro espécies nativas, sendo duas pioneiras e duas não pioneiras, com 30 sementes de cada espécie por repetição. Também, foram reservados cinco canteiros como controle, representados apenas pela remoção do solo superficial do canteiro, para simular uma situação de solo degradado, não sendo feita a transposição da serapilheira nem a semeadura das espécies nativas. Isso foi feito para a certeza de que as plântulas de espécies arbustivoarbóreas emergentes nos tratamentos 1, 2 e 3 foram realmente oriundas da semeadura direta e, ou, da serapilheira transposta.

As sementes foram adquiridas no Laboratório de Análise de Sementes Florestais (LASF) no Departamento de Engenharia Florestal da UFV.

Os tratamentos com serapilheira foram formados por amostras da camada de serapilheira de $1 \mathrm{~m}^{2} \mathrm{com}$ cerca de $5 \mathrm{~cm}$ de espessura, retiradas em vários pontos, aleatoriamente, em fragmento de Floresta Estacional Semidecidual secundária localizada no Campus da UFV, com o auxílio de um gabarito de madeira de $1 \mathrm{~m}^{2}$.

As espécies nativas utilizadas na semeadura direta foram: Senna macranthera (DC. ex Collad.) H. S. Irwin \& Barneby, Colubrina glandulosa Perkins, Tabebuia serratifolia (Vahl) G. Nicholse e Cedrela fissilis Vell. Para fins práticos de aplicação na restauração, espécies pioneiras e secundárias iniciais têm sido agrupadas como pioneiras, já que apresentam rápido crescimento e podem ser plantadas a pleno sol. Por sua vez, as espécies secundárias tardias e climácicas são agrupadas como não pioneiras, por apresentarem crescimento mais lento e longo ciclo de vida (MARTINS, 2007; 2009). Assim, $S$. macranthera e $C$. gladulosa foram agrupadas como pioneiras e $T$. serratifolia e $C$. fissilis, como não pioneiras.

No LASF, os lotes das sementes passaram por teste de germinação, em que foram mantidas no germinador à temperatura de $25^{\circ} \mathrm{C}$ e luz contínua por um período de $24 \mathrm{~h}$. O lote de sementes da espécie de $S$. macranthera obteve $80 \%$ de germinação, levando sete dias para início de sua germinação. O lote das sementes de C. glandulosa obteve $60 \%$ de germinação, com período de cinco a seis dias para início da germinação. O lote das sementes de $T$. serratifolia e de $C$. fissilis teve $70 \%$ de germinação, com um período de quatro a cinco dias para germinação. Todos esses processos foram analisados em laboratório, antes da semeadura direta nos canteiros.

As sementes das espécies $S$. macranthera e $C$. glandulosa necessitaram de tratamento para superação da dormência antes de serem semeadas nos canteiros do viveiro. Esse tratamento consistiu de imersão em ácido sulfúrico concentrado por $20 \mathrm{~min}$ para $S$. macranthera e 40 min para C. glandulosa e, em seguida, lavadas em água corrente. As espécies C. fissilis e T. serratifolia não necessitam de superação de dormência.

Todas as parcelas receberam irrigações diárias durante os nove primeiros meses de avaliação, exceto durante o período chuvoso.

O experimento foi avaliado durante dois anos, entre março de 2010 e março de 2012, em que todas as plântulas emergidas foram contadas e identificadas e tiveram medidos a altura e diâmetro ao nível do solo (DNS). Também, analisou-se a taxa de sobrevivência das plântulas emergidas, por meio da quantificação destas, mensalmente, com verificação de mortalidade de plântulas já quantificadas nos meses anteriores. Os resultados foram submetidos à análise de variância, utilizando o programa STATISTICA 7.0 (STATSOFT, 2004), com as médias dos tratamentos comparadas pelo teste de Tukey a 5\% de significância.

A identificação das plântulas em nível de família foi realizada com base no sistema filogenético proposto pelo APG III (2009). Os nomes científicos e respectivos

Revista Árvore, Viçosa-MG, v.39, n.5, p.811-820, 2015 
autores foram atualizados com os registros do Missouri Botanical Garden, através do endereço www.mobot.org.

As espécies arbustivo-arbóreas amostradas foram classificadas em categorias sucessionais, de acordo com os critérios propostos por Budowiski (1965) e adaptados por Gandolfi et al. (1995) para Florestas Semidecíduas brasileiras, sendo: pioneiras, secundárias iniciais, secundárias tardias e não classificadas.

A serapilheira acumulada foi avaliada por meio da retirada de todo o material orgânico (ramos, folhas, flores, frutos e sementes) depositado sobre o solo dos canteiros dos tratamentos 1,2 e 3, ao final dos dois anos da implantação do experimento, e posta para secar em estufa a $70{ }^{\circ} \mathrm{C}$ por $48 \mathrm{~h}$. Após a secagem, foi quantificada a massa total da serapilheira acumulada, referente às repetições dos três tratamentos.

Realizou-se a análise química do solo dos canteiros antes da montagem do experimento, em 2010, e após dois anos de sua implantação, em 2012, onde as espécies florestais foram semeadas. Retiraram-se, para cada ano de coleta (2010 e 2012), amostras simples de todos os canteiros, com os tratamentos 1, 2 e 3, nas profundidades de $0-10 \mathrm{~cm}$. As amostras simples foram misturadas para formar uma única amostra composta e, posteriormente, retirou-se uma porção de aproximadamente $0,3 \mathrm{~kg}$ para realização da análise química no Laboratório de Análise de Solos do Departamento de Solos da Universidade Federal de Viçosa.

\section{RESULTADOS}

Ao término do segundo ano de condução do experimento, no tratamento 1 (semeadura direta), do total das 150 sementes semeadas por espécie, emergiram e se estabeleceram 29 indivíduos de $S$. macranthera, cinco de $C$. glandulosa, dois de $T$. serratifolia e nenhum indivíduo de $C$. fissilis. No tratamento 2 (semeadura direta com transposição de serapilheira sobre as sementes), emergiram e se estabeleceram 85 indivíduos de $S$. macranthera, 81 de $C$. glandulosa, 59 de $T$. serratifolia e 18 indivíduos de $C$. fissilis. Já no tratamento 3 (transposição da serapilheira e semeadura direta sobre esta), emergiram e se estabeleceram 36 indivíduos de S. macranthera, 49 de C. glandulosa, 16 de T. serratifolia e quatro de $C$. fissilis.

As quatro espécies florestais nativas semeadas apresentaram emergência de plântulas aos 60 dias após a semeadura. Todas as espécies semeadas apresentaram diferença significativa entre as médias dos tratamentos, para a porcentagem de emergência de plântulas, com destaque para o tratamento 2, que exibiu valores superiores em relação aos demais (Figura 1).

A porcentagem de sobrevivência apresentou diferença significativa, pelo teste de Tukey a 5\% de significância, entre as médias dos tratamentos, apenas para a espécie $T$. serratifolia, com o tratamento 1 apresentando baixa porcentagem de sobrevivência para esta espécie, em relação aos demais tratamentos. As espécies pioneiras (C. glandulosa e S. macranthera) obtiveram maior porcentagem de sobrevivência que as espécies não pioneiras (C. fissilis e T. serratifolia) (Figura 1).

Em relação ao desenvolvimento das plântulas em altura, após dois anos da semeadura, não houve diferença significativa, entre as médias dos tratamentos, para a altura final das plântulas obtidas das espécies semeadas.

Em relação ao diâmetro médio final ao nível do solo (DNS) das plântulas obtidas das quatro espécies semeadas, houve diferença significativa entre as médias dos tratamentos apenas para a espécie C. glandulosa, com maior DNS médio final no tratamento 3. Para as demais espécies não houve diferença significativa entre as médias dos tratamentos (Figura 2).

No acompanhamento das plântulas arbustivoarbóreas emergidas nos tratamentos com a transposição de serapilheira durante o período de estudo, março de 2010 a março de 2012, obtiveram-se no tratamento 2 cinco espécies arbóreas advindas da serapilheira transposta; no tratamento 3, seis espécies arbóreas e uma arbustiva oriundas da serapilheira transposta. Já no tratamento 1, sem transposição de serapilheira, não se registrou emergência de plântulas de outras espécies além das semeadas (Tabela 1).

No tratamento 1, obtiveram-se 36 indivíduos arbóreos, provenientes apenas das sementes semeadas e no tratamento 2, 312 indivíduos arbóreos oriundos da semeadura e de sementes presentes na serapilheira transposta. No tratamento 3, obtiveram-se 140 indivíduos (139 arbóreos e um arbustivo) oriundos da semeadura e da serapilheira transposta. Nas repetições das parcelascontrole, houve emergência apenas de espécies herbáceas.

Entre as espécies arbustivas e arbóreas, ocorrentes nos tratamentos com serapilheira transposta (T2 e T3), 


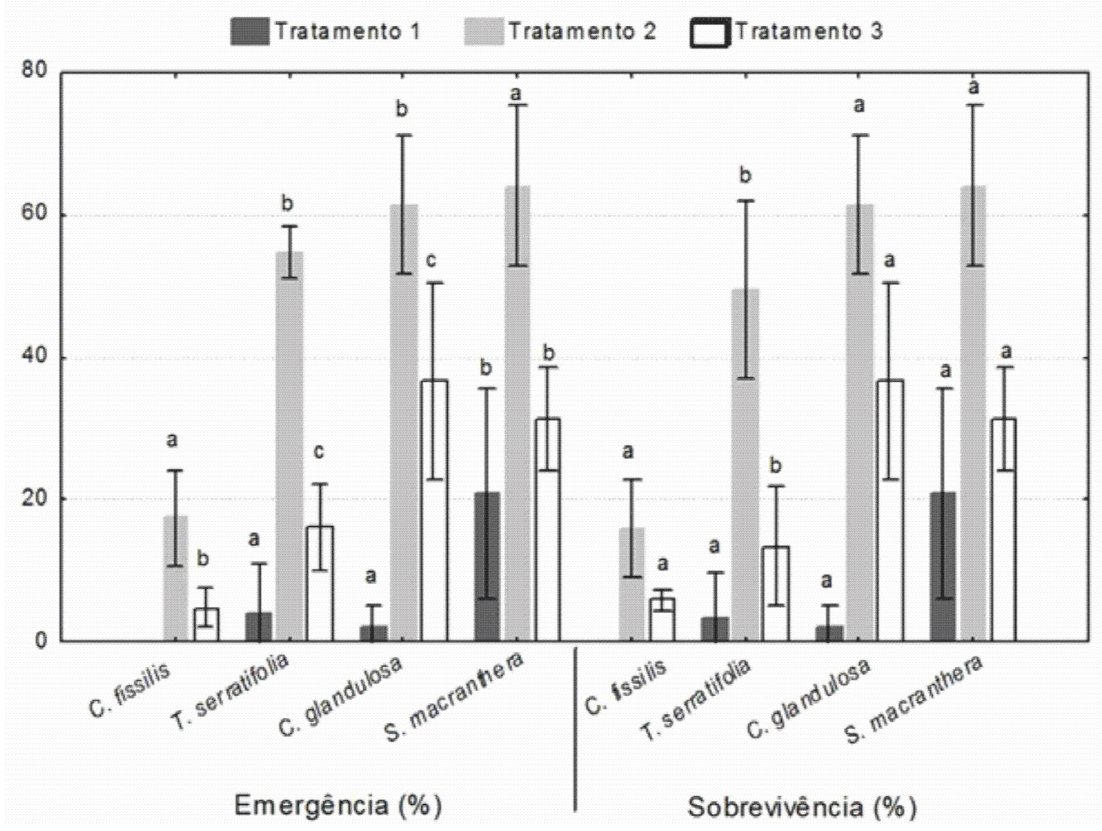

Figura 1 - Emergência das plântulas obtidas por semeadura, por tratamento, e sua sobrevivência após dois anos da semeadura direta. Barras verticais indicam o desvio-padrão. Valores seguidos de mesma letra dentro de cada grupo não diferem entre si, significativamente, pelo teste de Tukey $(p>0,05)$.

Figure 1 - Seedling emergence obtained by sowing by treatment, and survival after two years of direct sowing. Vertical bars indicate the standard deviation. Values followed by same letter within each group did not differ significantly by Tukey test $(p>0.05)$.

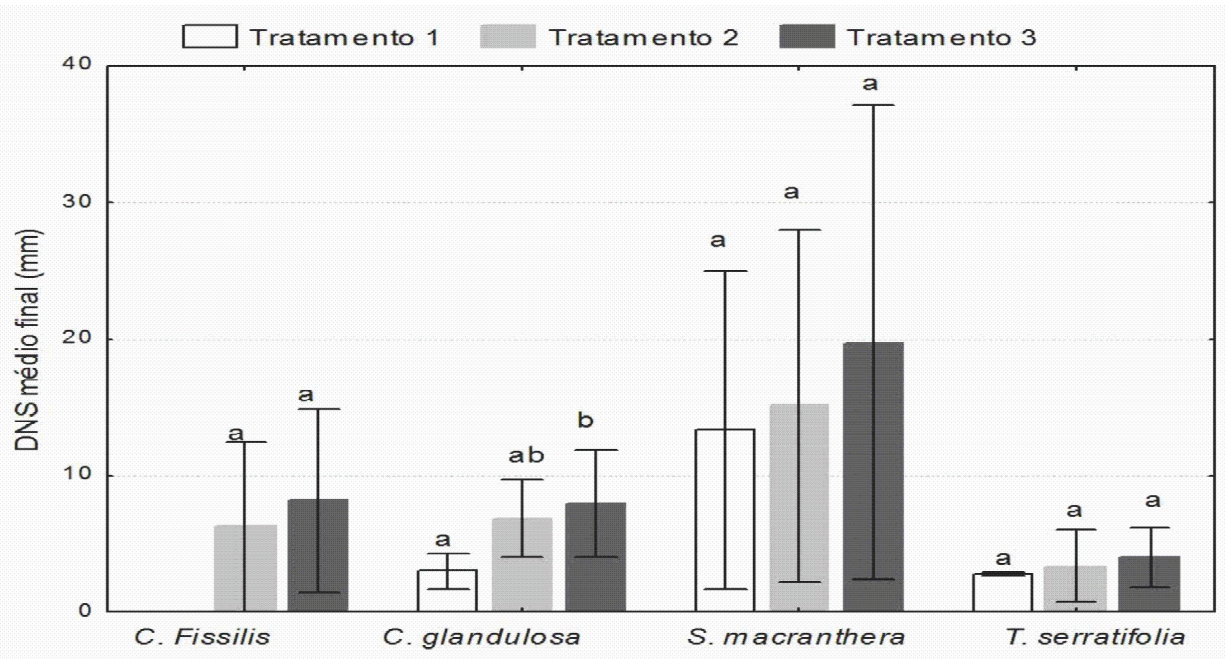

Figura2 - Diâmetro ao nível do solo (DNS) médio final das plântulas obtidas por semeadura, espécies semeadas por tratamento. Barras verticais indicam o desvio-padrão. Valores seguidos de mesma letra dentro de cada grupo não diferem entre si, significativamente, pelo teste de Tukey $(p>0,05)$.

Figure 2 - The final average diameter at soil level (DSL) of seedling obtained by sowing, seeded species per treatment. Vertical bars indicate the standard deviation. Values followed by same letter within each group did not differ significantly by Tukey test ( $p>0.05)$. 
Tabela 1 - Lista de plântulas de outras espécies obtidas nos tratamentos com transposição de serapilheira, com a respectiva classificação em grupos ecológicos e número total de indivíduos.

Table 1 - List of seedlings of other species obtained in treatments with transposition of litter, with respective classification in ecological groups and the total number of individuals.

\begin{tabular}{|c|c|c|c|c|c|}
\hline \multirow{2}{*}{ Espécie } & \multirow{2}{*}{ Família } & \multirow{2}{*}{ Grupo ecológico } & \multicolumn{3}{|c|}{$\mathrm{N}^{\mathrm{o}}$ indivíduos } \\
\hline & & & T1 & $\mathbf{T 2}$ & T3 \\
\hline Vernonia polyanthes (Spreng.) Less. & Asteraceae & Pioneira & 0 & 0 & 1 \\
\hline Trema micrantha (L.) Blume & Cannabaceae & Pioneira & 0 & 0 & 2 \\
\hline Pterogyne nitens Tul. & Fabaceae & Secundária inicial & 0 & 18 & 19 \\
\hline Senna multijuga (Rich.) H. S. Irwin \& Barneby & Fabaceae & Pioneira & 0 & 1 & 0 \\
\hline Miconia cinnamomifolia (DC.) Naudin & Melastomataceae & Pioneira & 0 & 0 & 1 \\
\hline Myrsine ferruginea (Ruiz \& Pav.) Spreng. & Primulaceae & Secundária inicial & 0 & 3 & 0 \\
\hline Solanum mauritianum Scop. & Solanaceae & Pioneira & 0 & 0 & 2 \\
\hline Cecropia glaziovi Snethl. & Urticaceae & Pioneira & 0 & 41 & 8 \\
\hline Cecropia hololeuca Miq. & Urticaceae & Pioneira & 0 & 6 & 2 \\
\hline Total de indivíduos registrados & & & $\mathbf{0}$ & 69 & 35 \\
\hline
\end{tabular}

$78 \%$ foram classificadas como pioneiras e $22 \%$, como secundárias iniciais. Entre os indivíduos arbustivos e arbóreos, $62 \%$ foram classificados como pioneiros e $38 \%$, como secundários tardios. Portanto, o grupo ecológico em maior abundância na serapilheira transposta foi o das pioneiras, representadas por sete espécies e as secundárias iniciais, por duas espécies.

A serapilheira acumulada no final de dois anos de análise do experimento, no somatório das 15 repetições dos três tratamentos, totalizando uma área de $15 \mathrm{~m}^{2}$, correspondeu a $414 \mathrm{~g} / \mathrm{m}^{2}$.

A partir da análise do solo, foi possível observar alterações em todos os seus atributos químicos nos dois períodos de comparação, antes da implantação do experimento e após dois anos, com valores superiores dos atributos acidez ativa do solo, P, K, cálcio trocável, magnésio trocável, CTC efetiva, CTC pH7, saturação de bases, matéria orgânica e fósforo remanescente na avaliação após dois anos de implantação do experimento (Tabela 2).

O solo na camada de $0-10 \mathrm{~cm}$, na avaliação de dois anos após a implantação do experimento, apresentou acidez ativa do solo fraca; baixo teor de fósforo disponível; teor de potássio disponível muito bom; cálcio trocável e magnésio trocável com valores considerados médio; acidez trocável muito baixa; soma de bases, CTC efetiva e CTC pH 7 considerada média; boa saturação por bases; saturação por alumínio muito baixa; baixo teor de matéria orgânica; e fósforo remanescente muito baixo (ALVAREZ et al., 1999).

\section{DISCUSSÃO}

Das espécies pioneiras semeadas ( $S$. macranthera e C. glandulosa) foi obtido maior número de plântulas propiciado pelo ambiente mais favorável à situação de maior incidência luminosa, já que os canteiros dos tratamentos estavam a pleno sol. Essas espécies melhoram as condições ambientais, por terem crescimento mais rápido e propiciarem ambiente mais favorável ao posterior desenvolvimento das espécies tardias, as quais necessitam de maior sombreamento e são importantes para o avanço sucessional da área.

O tratamento 2 favoreceu melhores condições para a emergência das plântulas, como a proteção das sementes da radiação solar direta e a manutenção de umidade e temperatura mais adequadas para o favorecimento da germinação propiciado pela serapilheira transposta, além de a sua decomposição ter favorecido, ao longo do tempo, o fornecimento de matéria orgânica para as plântulas.

O tratamento 3 mostrou-se inferior ao tratamento 2 , pois, como as sementes do primeiro foram semeadas sobre a serapilheira, estas ficaram mais expostas à radiação solar direta e, possivelmente, não conseguiram manter a umidade necessária para sua germinação. Além disso, a camada de serapilheira também pode ter impedido a chegada de algumas dessas sementes ao solo. Mas as sementes que alcançaram o solo e conseguiram angariar a umidade necessária obtiveram sucesso em sua germinação e emergência da plântula. 
Tabela 2 - Resultados da análise química das amostras de solo coletadas nos canteiros do Viveiro Florestal, nas parcelas com os tratamentos 1,2 e 3 , antes da implantação do experimento (A) e dois anos depois (B).

Table 2 - Results of chemical analysis for soil samples collected in the beds of the Forest Nursery, in the plots with treatments 1, 2 and 3, before deployment of the experiment $(A)$ and two years later $(B)$.

\begin{tabular}{lcc}
\hline \multirow{2}{*}{ Atributos } & \multicolumn{2}{c}{ Amostra $0-10 \mathrm{~cm}$} \\
\cline { 2 - 3 } & $\mathrm{A}$ & $\mathrm{B}$ \\
\hline $\mathrm{pH} \mathrm{H} 20$ & 6,17 & 6,39 \\
$\mathrm{P}\left(\mathrm{mg} / \mathrm{dm}^{3}\right)$ & 3,70 & 4,10 \\
$\mathrm{~K}\left(\mathrm{mg} / \mathrm{dm}^{3}\right)$ & 55,00 & 156,00 \\
$\mathrm{Ca}^{2}\left(\mathrm{cmolc}^{2} \mathrm{dm}^{3}\right)$ & 1,54 & 2,37 \\
$\mathrm{Mg}^{2}\left(\mathrm{cmolc} / \mathrm{dm}^{3}\right)$ & 0,37 & 0,53 \\
$\mathrm{Al}\left(\mathrm{cmolc} / \mathrm{dm}^{3}\right)$ & 0,00 & 0,00 \\
$\mathrm{H}+\mathrm{Al}\left(\mathrm{cmolc} / \mathrm{dm}^{3}\right)$ & 1,40 & 1,50 \\
$\mathrm{SB}\left(\mathrm{cmolc} / \mathrm{dm}^{3}\right)$ & 2,05 & 3,30 \\
$(\mathrm{t})\left(\mathrm{cmolc} / \mathrm{dm}^{3}\right)$ & 2,05 & 3,30 \\
$\mathrm{~T}\left(\mathrm{cmolc} / \mathrm{dm}^{3}\right)$ & 3,45 & 4,80 \\
$\mathrm{~V}(\%)$ & 59,40 & 68,80 \\
$\mathrm{~m}(\%)$ & 0,00 & 0,00 \\
$\mathrm{MO}(\mathrm{dag} / \mathrm{kg})$ & 0,78 & 1,96 \\
$\mathrm{P}-\mathrm{rem}(\mathrm{mg} / \mathrm{L})$ & 18,40 & 20,6 \\
\hline
\end{tabular}

pH em água - relação 1:2,5; P - K - Extrator Mehlich 1; Ca - MG - Al - Extrator: $\mathrm{KCl}-1 \mathrm{~mol} / \mathrm{L} ; \mathrm{H}+\mathrm{Al}$ - Extrator Acetato de Cálcio $0,5 \mathrm{~mol} / \mathrm{L}-\mathrm{pH} 7,0 ; \mathrm{SB}=$ Soma de Bases Trocáveis; $(\mathrm{t})$ - Capacidade de Troca Catiônica Efetiva; (T) - Capacidade de Troca Catiônica a pH 7,0; V = Índice de Saturação de Bases; $\mathrm{m}=$ Índice de Saturação de Alumínio; MO = Matéria Orgânica - C. Org x 1,724 - WalkleyBlack; P-rem = Fósforo remanescente.

No tratamento 1, as sementes ficaram totalmente expostas à radiação solar direta. Espécies herbáceas e gramíneas cresceram nesse ambiente, favorecidas pela superfície descoberta do solo. Esse fato pode ter dificultado a germinação das sementes das espécies nativas semeadas. Outro fator possível de limitação da germinação está ligado à ausência da transposição da serapilheira, não havendo sombreamento do solo nem impedimento físico para o desenvolvimento de espécies herbáceas e gramíneas.

No Município de Morro Agudo, Estado de São Paulo, ao utilizar o método de semeadura direta, com 20 espécies nativas, verificou-se em um dos experimentos conduzidos em campo que não houve germinação das espécies semeadas (ARAKI, 2005). Este autor atribui esse fato, provavelmente, à competição com a gramínea invasora Urochloa decumbens (Stapf) R.D. Webster.

C. fissilis e T. serratifolia alcançaram melhores taxas de sobrevivência nos tratamentos 2 e 3 , favorecidas pela utilização da serapilheira, que possibilitou melhores condições para o estabelecimento dessas espécies, uma vez que pertencem ao grupo ecológico que não toleram ambientes abertos.

As espécies pioneiras obtiveram boa taxa de sobrevivência, não apresentando diferença significativa entre tratamentos. Essas espécies toleram e se desenvolvem bem em ambientes com alta incidência luminosa e são boas opções para áreas abertas a serem restauradas.

As espécies não pioneiras são mais recomendadas para a semeadura de enriquecimento, após as espécies pioneiras estarem mais desenvolvidas e propiciarem condições mais adequadas para que elas se desenvolvam, como um ambiente com menor incidência luminosa e mais sombreado.

Na semeadura direta, é importante avaliar as espécies a serem utilizadas para a restauração, bem como as condições ambientais do local a ser restaurado, como presença de gramíneas invasoras e condições edáficas, que influenciarão na efetividade da restauração (ISERNHAGEN; GUERIN, 2011). Esses autores destacaram que, de acordo com as literaturas científicas brasileiras sobre semeadura direta de espécies arbóreas nativas, esse método é promissor por ser técnica e economicamente viável, sobretudo para ocupação inicial em áreas agrícolas abandonadas, onde o poder de resiliência foi comprometido.

Em relação ao desenvolvimento em altura das plântulas obtidas da semeadura direta, não houve diferença significativa para as espécies entre as médias dos tratamentos em razão, possivelmente, da grande variação no valor da altura dos indivíduos, em detrimento dos diferentes períodos de emergência destes.

O diâmetro médio final no nível do solo das plântulas obtidas das espécies semeadas apresentou diferença significativa apenas para a espécie $C$. glandulosa, com melhor resultado no tratamento 3, possivelmente por apresentar menor competição entre indivíduos em relação ao tratamento 2 , em que ambos os tratamento receberam a deposição da serapilheira, mas no tratamento 2 houve maior número de plântulas emergidas, com maior competição por recurso, como água e nutrientes, entre elas.

A transposição da serapilheira é uma forma de restaurar áreas degradadas. A serapilheira contém

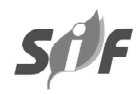

Revista Árvore, Viçosa-MG, v.39, n.5, p.811-820, 2015 
sementes dispersas pelas árvores que ajudam no enriquecimento das áreas a serem restauradas, juntamente com a semeadura direta. Além disso, pode inibir a emergência e desenvolvimento de espécies gramíneas invasoras e a consequente competição destas por nutrientes. Nos tratamentos 2 e 3, pode-se observar claramente esse fato, em que houve a emergência de plântulas de espécies arbustivo-arbóreas advindas da transposição da serapilheira. Isso proporcionou maior riqueza de espécies e melhores condições edáficas.

A camada de serapilheira proporciona maior infiltração e retenção de água no solo, reduzindo o escoamento superficial, além de fornecer nutriente e matéria orgânica para as sementes existentes no banco de sementes do solo (RODRIGUES et al., 2010). Esse processo forma um ciclo dentro da floresta, o que resulta na ciclagem de nutrientes, contribuindo, assim, para a restauração ecológica. Dessa forma, o tratamento 2 propiciou a emergência e desenvolvimento de maior número de indivíduos, mostrando-se mais interessante para a restauração florestal, pelo fato de cobrir rapidamente a área com espécies arbustivo-arbóreas e impedir que espécies invasoras estabeleçam na área e dificultem ou, mesmo, impeçam o processo de restauração.

O predomínio de espécies e indivíduos pioneiros oriundos da transposição da serapilheira nos tratamentos 2 e 3 corrobora com Rodrigues et al. (2010) em estudo sobre transposição de serapilheira e banco de sementes do solo para fins de restauração florestal, em que houve predomínio de espécies do grupo ecológico das pioneiras com $74 \%$ das espécies pertencentes a esse grupo. Araujo et al. (2001) constataram maior densidade de sementes em floresta em estágio inicial de sucessão, ocorrendo maior número de espécies pioneiras, que compõem o banco de sementes persistente do solo. O elevado número de espécies e indivíduos pioneiros apresenta grande importância para a rápida cobertura do solo, propiciando condições edafoclimáticas e de sombreamento favoráveis para o desenvolvimento das espécies tardias e condições desfavoráveis para gramíneas invasoras e competidoras. As espécies pioneiras são espécies dependentes de luz e se desenvolvem em bordas de florestas ou clareiras (GANDOLFI et al., 1995).

A serapilheira acumulada $\left(414,2 \mathrm{~g} / \mathrm{m}^{2}\right)$, no somatório das 15 repetições dos três tratamentos com semeadura (T1, T2 e T3), foi superior àquela obtida por Miranda Neto (2011), em estudo realizado em uma floresta restaurada, após 40 anos do plantio, em Viçosa, MG, tendo obtido 343,2 g/m². A serapilheira é a principal via de transferência no fluxo de nutrientes e essencial para a sustentabilidade de uma floresta. Além de permitir a melhoria da fertilidade do solo através do retorno de significativa quantidade de nutrientes absorvida pelas plantas (FERREIRA et al., 2007) e colaborar como subsídio fundamental no processo de restauração ecológica de ecossistemas degradados.

O potássio $(\mathrm{K})$, elemento que desempenha inúmeras funções nas plantas, como participação em processos osmóticos, síntese de proteínas, abertura e fechamento de estômatos, permeabilidade da membrana, controle do $\mathrm{pH}$, entre outras (MALAVOLTA et al., 1997), teve sua disponibilidade no solo aumentada após a adição da serapilheira. Esse grande aumento se deu porque, em geral, o K é o nutriente de mais rápida liberação na serapilheira em todos os ecossistemas (GAMARODRIGUES, 1997).

O teor de matéria orgânica que se elevou na análise realizada em 2012 é devido, principalmente, à decomposição da serapilheira, que constitui o principal meio de transferência de matéria orgânica e elementos minerais da vegetação para o solo (VITAL et al., 2004; PINTO et al., 2009).

A elevação da fertilidade do solo refletiu-se no aumento da saturação por bases (V), após os tratamentos, bem como no aumento da CTC. Os resultados assemelham-se aos de Alcântara et al. (2000), que ao incorporarem biomassa vegetal ao solo obtiveram aumentos significativos na saturação por bases e CTC efetiva do solo.

Dessa forma, pode-se observar melhoria em todos os atributos da análise química feita no solo dos canteiros do Viveiro de Pesquisas, onde foi conduzido o experimento após os dois anos de sua implantação e estudo. Esse fato evidencia que há disponibilização no solo de nutrientes através da ciclagem de nutrientes ocorrida pela produção e decomposição da serapilheira depositada pelas espécies arbustivo-arbóreas emergidas e estabelecidas nos canteiros com os respectivos tratamentos testados.

\section{CONCLUSÕES}

A semeadura direta das sementes com posterior cobertura de serapilheira mostrou-se técnica viável 
de nucleação, pois propiciou maior porcentagem de emergência e número de plântulas estabelecidas após o processo de semeadura.

A transposição da serapilheira enriquece o sítio a ser restaurado com outras espécies arbustivo-arbóreas, além das utilizadas na semeadura direta. Além disso, pode propiciar aumento da fertilidade do solo superficial e ciclagem de nutrientes no sistema.

S. macranthera e C. glandulosa foram as espécies com maior número de emergência de plântulas $\mathrm{e}$, portanto, apresentam potencial para uso em projetos de restauração ecológica, através de semeadura direta em áreas degradadas mais abertas.

\section{AGRADECIMENTOS}

À CAPES, à FAPEMIG e ao CNPq, pela concessão das bolsas de estudo; e ao CNPq, pela bolsa de Produtividade em Pesquisa ao segundo autor.

\section{REFERÊNCIAS}

ALCÂNTARA, F.A.; FURTINI NETO, A.E.; PAULA, M.B.; MESQUITA, H.A.; MUNIZ, J.A. Adubação verde na recuperação da fertilidade de um Latossolo Vermelho-Escuro degradado.

Pesquisa Agropecuária Brasileira, v.35, n.2, p.277-288, 2000.

ALVAREZ V., V.H.; NOVAIS, R.F.; BARROS, N.F.; CANTARUTTI, R.B.; LOPES, A.S. Interpretação dos resultados das análises de solo. In: RIBEIRO, A.C.; GUIMARÃES, P.T.G.; ALVAREZ V., V.H. (Ed.). Recomendações para o uso de corretivos e fertilizantes em Minas Gerais - 5 A Aproximação. Viçosa, MG: CFSEMG. 1999. p.25-32.

ANDRADE, A.G.; TAVARES, S.R.L.; COUTINHO, H.L.C. Contribuição da serapilheira para recuperação de áreas degradadas e para manutenção da sustentabilidade de sistemas agroecológicos. Informe Agropecuário, v.24, n.220, p.55-63, 2003.

ANGIOSPERM PHYLOGENY GROUP III. APG III. An update of the Angiosperm Phylogeny Group classification for the orders and families of flowering plants. Botanical Journal of the Linnean Society, v. 161, p.105-121, 2009.
ARAKI, D.F. Avaliação da semeadura a lanço de espécies florestais nativas para recuperação de áreas degradadas. 2005. 150f. Dissertação (Mestrado em Ecologia de Agroecossistemas) Escola Superior de Agronomia Luiz de Queiroz, Universidade de São Paulo, Piracicada, 2005.

ARAUJO, M.M.; OLIVEIRA, F.A.; VIEIRA, I.C.G.; BARROS, P.L.C.; LIMA, C.A.T. Densidade e composição florística do banco de sementes do solo de florestas sucessionais na região do Baixo Rio Guamá, Amazônia Oriental. Scientia Florestalis, n.59, p.115-130, 2001.

BUDOWISKI, G. Distribution of tropical american rain forest species in the light of successional processes. Turrialba, v.15, n.1, p. $40-42,1965$.

CASTRO, P.S.; VALENTE, O.F.; COELHO, D.T.; RAMALHO, R.S. Interceptação da chuva por mata natural secundária na região de Viçosa, MG. Revista Árvore, v.7, n.1, p.76-89, 1983.

CIANCIARUSO, M.C.; PIRES, J.S.R.; DELITTI, W.B.C.; SILVA, E.F.L.P. Produção de serapilheira e decomposição do material foliar em um cerradão na Estação Ecológica de Jataí, município de Luiz Antônio, SP, Brasil. Acta Botanica Brasilica, v.20, n.1, p.49-59, 2006.

FERREIRA, R.L.C.; LIRA JÚNIOR, M.A.; ROCHA, M.S.; SANTOS, M.V.F.; LIRA, M.A.; BARRETO, L.P. Deposição e acúmulo de matéria seca e nutrientes em serapilheira em um bosque de sabiá (Mimosa caesalpiniifolia Benth.). Revista Árvore, v.31, n.1, p.7-12, 2007.

FERREIRA, R.A. Estudo da semeadura direta visando à implantação de matas ciliares. 2002. 138f. Tese (Doutorado em Fitotecnia) - Universidade Federal de Lavras, Lavras, 2002.

GAMA-RODRIGUES, A.C. Ciclagem de nutrientes por espécies florestais em povoamento puros e mistos, em solos de tabuleiros da Bahia, Brasil. 1997. 107f. Tese (Doutorado em Solos e Nutrição de Plantas) - Universidade Federal de Viçosa, Viçosa, MG, 1997.

Revista Árvore, Viçosa-MG, v.39, n.5, p.811-820, 2015 
GANDOLFI, S.; LEITÃO FILHO, H.F.; BEZERRA, C.L.F. Levantamento florístico e caráter sucessional das espécies arbustivo-arbóreas de uma floresta semidecídua no município de Guarulhos, SP. Revista Brasileira de Biologia, v.55, n.4, p.753-767, 1995.

ISERNHAGEN, I.; GUERIN, N. Avanços e próximos desafios da semeadura direta para restauração ecológica. In: BARBOSA, L.M. (Coord.) SIMPÓSIO DE RESTAURAÇÃO ECOLÓGICA, 6., 2011, São Paulo. Anais... São Paulo: Instituto de Botânica - SMA, 2011. p.201208.

KAGEYAMA, P.Y.; GANDARA, F.B. Recuperação de áreas ciliares. In: RODRIGUES, R.R.; LEITÃOFILHO, H.F. (Ed.). Matas ciliares: conservação e recuperação. 2.ed. São Paulo: EDUSP, 2004. p.249-269.

MALAVOLTA, E.; VITTI, G.C.; OLIVEIRA, S.A. Avaliação do estado nutricional das plantas. Piracicaba: Associação Brasileira para a Pesquisa da Potassa e do Fosfato, 1997. 319p.

MARTINS, S.V. Recuperação de áreas degradadas: ações em Áreas de Preservação Permanente, voçorocas, taludes rodoviários e de mineração. Viçosa, MG: Aprenda Fácil, 2009. 270p.

MARTINS, S.V. Recuperação de matas ciliares. 2.ed. rev. e ampl. Viçosa, MG: Aprenda Fácil, 2007. 255p.

MENEGHELLO, G.E.; MATTEI, V.L. Semeadura direta de timbaúva (Enterolobium contortisiliquum), canafístula (Peltophorum dubium) e cedro (Cedrela fissilis) em campos abandonados. Ciência Florestal, v.14, n.2, p.21-27, 2004.
MIRANDA NETO, A. Avaliação do componente arbóreo, da regeneração natural e do banco de sementes de uma floresta restaurada com 40 anos, Viçosa, MG. 2011. 146f. Dissertação (Mestrado em Ciência Florestal) - Universidade Federal de Viçosa, Viçosa, MG, 2011.

MISSOURI BOTANICAL GARDEN. Disponível em: $<$ http://www.mobot.org $>$. Acesso em: 12 de abr. de 2012.

MORAES, R.M.; DELITTI, W.B.C.; RINALDI, M.C.S.; REBELO, C.F. Ciclagem mineral em Mata Atlântica de encosta e mata sobre restinga, Ilha do Cardoso, SP: nutrientes na serapilheira acumulada. In: SIMPÓSIO DE ECOSSISTEMAS BRASILEIROS, 4., 1998, Águas de Lindóia. Anais... Águas de Lindóia: ACIESP, 1998. p.71-7.

PINTO, S.I.C.; MARTINS, S.V.; BARROS, N.F.; DIAS, H.C.T. Ciclagem de nutrientes em dois trechos de floresta estacional semidecidual na reserva florestal Mata do Paraíso em Viçosa, MG, Brasil. Revista Árvore, v.33, n.4, p.653-663, 2009.

RODRIGUES, B.D.; MARTINS, S.V.; LEITE, H.G. Avaliação do potencial da transposição da serapilheira e do banco de sementes do solo para restauração florestal em áreas degradadas.

Revista Árvore, v.34, n.1, p.65-73, 2010.

SMITH, D.M. The practice of silviculture. 8.ed. New York: John Wiley, 1986. 527 p.

STATSOFT, Inc. Statistica - Data analysis software system. Version 7.0.61.0. Tulsa: 2004.

VITAL, A.R.T.; GUERRINI, I.A.; FRANKEN,W.K.; FONSECA, R.C.B. Produção de serapilheira e ciclagem de nutrientes de uma floresta estacional semidecidual em zona ripária. Revista Árvore, v.28, n.6, p.793-800, 2004. 